\title{
Manajemen Peta Jalan (Roadmap) Persandian Pemerintah Daerah Di Indonesia
}

\author{
R Wisnu Prio Pamnungkas', Rakhmi Khalida² \\ Universitas Bhayangkara \\ Jl Raya Perjuangan Marga Mulya, Bekasi Utara, (021) 88955882 \\ wisnu.prio@dsn.ubharajaya.ac.id ${ }^{1)}$,rakhmi.khalida@dsn.ubharajaya.ac.id²)
}

\begin{abstract}
The present coding is safeguarding public information, not only guaranteeing security against confidentiality, but on aspects of integrity, authenticity, accessibility, availability and nondenial of information. Security is not only in the password room and is not only done by Sandiman, but more broadly to safeguard ICTs and col-laborate with information security management systems. In order to carry out these functions, it is necessary to make a road map which is a detailed work plan for coding operations. The research method used is descriptive made with reference to Planning, Implementation, Monitoring and Evaluation and Reporting. The results achieved in this study are roadmaps that can be used as a reference for regional governments in the Indonesian territory.
\end{abstract}

Keywords: Encryption, Authenticity, Accessibility, Availability, Roadmap

\begin{abstract}
Abstrak
Persandian sekarang adalah pengamanan informasi publik, bukan hanya jaminan keamanan terhadap aspek kerahasiaan, tetapi terhadap aspek keutuhan, keotentikan, keteraksesan, ketersediaan, dan penyangkalan terhadap informasi. Pengamanan bukan hanya di kamar sandi dan tidak hanya dilakukan oleh sandiman, tetapi lebih luas ke pengamanan TIK dan berkolaborasi dengan sistem manajemen keamanan informasi. Agar dapat melaksanakan fungsi-fungsi tersebut, perlu dibuat peta jalan (Roadmap) yang merupakan rencana ker-ja rinci penyelenggaraan persandian. Metode penelitian yang digunakan adalah deskriptif yang mengacu pada pada Perencanaan, Pelaksanaan, Pemantauan dan Evaluasi serta Pelaporan. Hasil yang dicapai pada penelitian ini adalah roadmap persandian yang dapat dijadikan acuan pemerintah daerah di wilayah Indonesia.
\end{abstract}

Kata kunci: Enkripsi, Keaslian, Aksesibilitas, Ketersediaan, Peta Jalan

\section{PENDAHULUAN}

Beralihnya tata kelola pemerintah menuju era digital, memunculkan inovasi-inovasi baru, khu-susnya dalam hal penyelenggaraan pemerintahan, pelayanan publik, komunikasi publik dan sebagainya [1][2]. Pemanfaatan teknologi sebagai upaya transparansi, mempercepat respon dan pe-layanan, serta efisiensi sumber daya, tetapi di balik kemudahan yang didapat tersebut berpotensi menimbulkan ancaman keamanan informasi. Upaya keamanan informasi perlu dilakukan berupa pengamanan aplikasi dan sistem elektronik, dalam hal ini peran persandian dan keamanan informasi dibutuhkan, sebagai entitas pengaman informasi melalui penyelenggaraan persandian [2].

Persandian atau dikenal dengan sebutan kriptologi adalah kegiatan di bidang pengamanan informasi rahasia yang dilaksanakan dengan menerapkan konsep, teori, dan seni dari ilmu kripto beserta ilmu pendukung 
lainnya secara sistematis, metodologis, dan konsisten serta terikat pada etika profesi sandi. [3]. Menurut Peraturan Pemerintah Republik Indonesia No. 7 dan No. 9 Tahun 2016 dalam menyelenggarakan persandian, instansi pemerintah harus me-nyelenggarakan pengendalian persandian di lingkungan instansinya masing-masing sesuai dengan kebijakan persandian [7][8]. Melihat kondisi tersebut peningkatan kompetensi sumber daya manusia (SDM) persandian dalam pengamanan informasi, keamanan aplikasi atau sistem elektronik di lingkungan menjadi sangat penting [4]. Fungsi persandian sekarang berbeda dengan fungsi persandian sebelumnya. Jika sebelumnya urusan persandian hanya sebatas pengamanan berita rahasia, sangat tertutup, dilaksanakan oleh sandiman, dan belum menyatu dengan TIK, maka sekarang persandian mencakup fungsi yang lebih luas. Berdasarkan Undang-Undang Re-publik Indonesia No. 14 Tahun 2008 Tentang Keterbukaan Informasi Publik persandian sekarang adalah pengamanan informasi publik, bukan hanya jaminan keamanan terhadap aspek kerahasiaan, tetapi terhadap aspek keutuhan, keotentikan, keteraksesan, ketersediaan, dan pen-yangkalan terhadap informasi [5].

Persandian memberikan pelayanan bukan hanya kepada pimpinan daerah tetapi juga perangkat daerah termasuk staff [6]. Pengamanan bukan hanya di kamar sandi dan tidak hanya dilakukan oleh sandiman, tetapi lebih luas ke pengamanan TIK dan berkolaborasi dengan sistem manajemen keamanan informasi. Pada prakteknya dengan memiliki Roadmap persandian pada setiap daerah di Indonesia dapat memberikan kemudahan dalam penyusunan rencana kerja dan kegiatan di bidang persan-dian masa depan sehingga fungsi pengamanan informasi publik dapat terlaksana dengan baik [12]. Sasaran penyusunan Roadmap persandian yaitu semua pihak stakeholder yang terkait akan persandian pada Dinas Komunikasi dan Informatika pemerintah daerah. Manajemen Roadmap dapat menjadi salah satu solusi dalam rangka dapat melaksanakan fungsi-fungsi tersebut di atas.

Sampai saat ini kesadaran akan Roadmap persandian masih sangat kurang. Berdasarkan studi dari Ahmad Budiman pada tahun 2016 praktek persandian belum dapat dilaksanakan secara merata kualitasnya. Jenis resiko dan ancaman yang paling mendominasi adalah terbatasnya SDM sandi berkualifikasi ahli sandi dan kemampuan pemerintah menetapkan informasi berklasifikasi. [1]. Peran Lembaga Sandi Negara selaku pembina tunggal persandian perlu memfasilitasi pengembangan kompetensi dengan menyelenggarakan Diklat fungsional maupun Diklat teknis yang aplikatif [4]. Setiap daerah dan kota yang mengadopsi smart city perlu menentukan ruang lingkup Roadmap persandian. Lingkup Roadmap persandian yang dapat diimplementasikan pada pemerintah daerah di Indonesia adalah melakukan identifikasi terkait aspek-aspek apa saja yang akan dikembangkan, meliputi infrastruktur dan perangkat keras, sistem informasi, aplikasi, layanan dan SDM, lalu melakukan environment scanning untuk memberikan gambaran tentang kondisi SDM persandian saat ini, lalu menentukan sasaran jangka menengah untuk memperoleh sasaran strategis, menyusun program dan 
rencana kegiatan secara rinci, dan menyusun draft Roadmap [9][10][11]. Ruang lingkup tersebut dapat memperkecil hambatan setiap pemerintah daerah untuk memiliki Roadmap persandian.

\section{METODOLOGI PENELITIAN}

Roadmap merupakan peta atau panduan yang digunakan sebagai petunjuk arah jalan. Roadmap adalah rencana rinci yang memuat tahapan sistematis mengenai pelaksanaan suatu program kegiatan dalam kurun waktu tertentu [3]. Menurut bidang umum Lembaga Sandi Negara fungsi persandian pada Pemerintah Kabupaten/Kota [4] adalah sebagai berikut.

A. Tata Kelola Penjaminan Keamanan Informasi Berklasifikasi,

B. Pengelolaan Sumber Daya Persandian

C. Dukungan Layanan Operasional Persandian untuk Keamanan Informasi.

D. Pengawasan Penyelenggaraan Persandian untuk Keamanan Informasi Internal.

Metodologi Pembuatan Roadmap Persandian adalah sebagai berikut.

A. Metode Pengumpulan Data

Dalam membuat kajian ini, penulisan melakukan pengumpulan data dengan Studi pustaka.

1) Studi Pustaka

Hal ini dilakukan untuk pendekatan secara teori dan konsep pendukung terhadap masalah yang dikaji.

2) Observasi

Menggunakan metode ini dengan cara melakukan pengamatan langsung di Dinas Komunikasi dan informatika dan website lain yang berkaitan dengan tujuan agar mendapatkan data yang relevan dan lebih rinci sehingga dapat memperoleh data-data yang diperlukan dalam penelitian.

3) Wawancara

Melakukan kunjungan langsung ke Dinas Komunikasi dan Informatika dan bertemu lang-sung untuk melakukan wawancara dengan seksi Persandian.

B. Tahapan Penyusunan Roadmap

Pada tahapan ini adalah melakukan serangkaian kegiatan berikut, yaitu :

1) Keadaan Sebelum dan Saat ini (sebagai bentuk Baseline).

Keadaan Sebelum dan Keadaan Saat ini adalah, di mana data-data sebagai informasi dari perusahaan / organisasi yang dibutuhkan dalam menyusun kebutuhan rancangan roadmap.

2) Tujuan yang Ingin Dicapai

Tujuan apa yang akan dicapai, harus sudah ditentukan terlebih dahulu di awal. Diketahui dan dipahami bersama oleh tim. 
Sehingga semua yang memahami peranan penyusunan roadmap ini mengerti, paham dan akan meng-implementasikan-nya

3) Sasaran dari Setiap Tahap

Roadmap pada umumnya di awali dengan pembahasan Grand Design atau Blue Print yang sudah dimiliki. Pembahasan Rencana Kerja Jangka Panjang, selalu memiliki poin-poin ter-tentu yang dapat digunakan untuk pembahasan yang lebih rinci dan dapat digunakan se-bagai penyusunan roadmap dengan jangka waktu yang lebih pendek.

4) Indikator Pencapaian Sasaran

Sesuai dengan hal di atas, bahwa sasaran-sasaran pada tahapantahapan pelaksanaan roadmap penting untuk memudahkan dalam hal monitoring dan evaluasi pelaksanaan. Maka, masing-masing tahapan tersebut harus memiliki indikator pencapaian. Yaitu indikator keberhasilan dari sebuah sasaran.

Dengan adanya indikator ini, kita sebagai penyusun roadmap akan dapat dengan mudah proses pelaksanaan dan monitoring evaluasi kegiatan. Apakah pelaksanaan tersebut sudah mencapai sasaran? Ataukah sudah terpenuhinya indikator pencapaian? Atau bahkan, indikasi-indikasi apa yang dapat menandakan bahwa sasaran-sasaran tersebut tercapai sehingga standar keberhasilan yang diperoleh dapat dibentuk / disiapkan sejak dini.

\section{HASIL DAN PEMBAHASAN}

Tahapan ini merupakan penjelasan mengenai tahapan yang akan dilakukan saat proses penyusunan Roadmapp Adapun tahapan-tahapan tersebut dapat tergambar sebagai berikut.

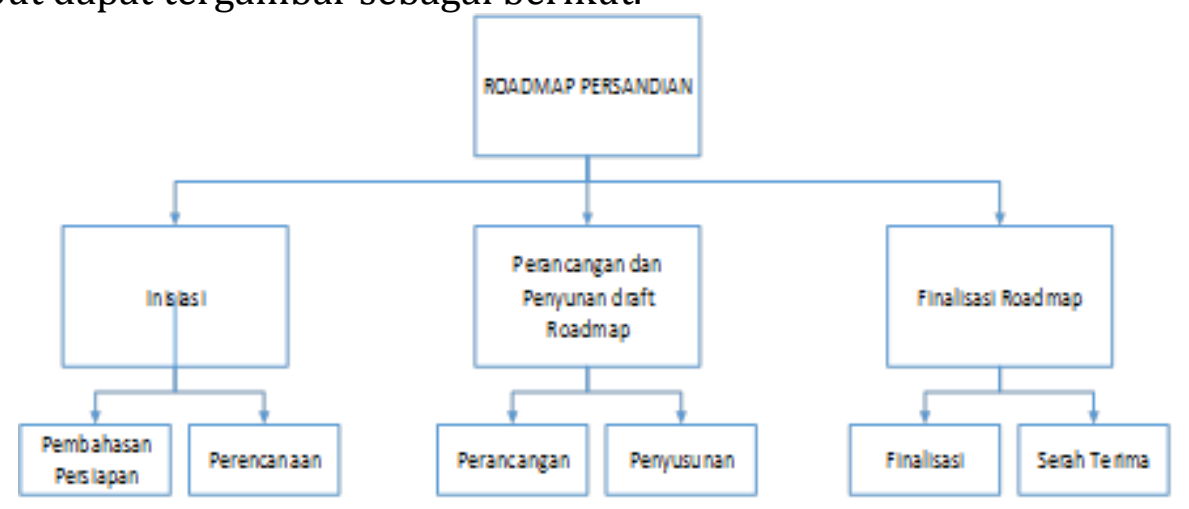

Gambar 1. Work Breakdown Structure Roadmap Persandian

Penjelasan dari tahapan-tahapan tersebut dapat dijelaskan sebagai berikut : 1. Inisiasi

Dalam tahap ini, pembahasan yang dilakukan lebih pada konfirmasi kebutuhan pengguna (User Requirement). Pembahasan dengan user-user terkait akan sangat berarti dalam melaksanakan kegiatan penyusunan Roadmap persandian, dari sumber data dan informasi hingga perencanaan 
kebutuhan kedepan dalam kurun waktu beberapa tahun. Bentuk pembahasan akan dituangkan pada dokumen sebagai bagian dari Pelaporan pelaksaan di awal kegiatan sesuai pada tahapan Inisiasi, dengan menandakan aktifitas Kick Of Meeting untuk kegiatan bisa dimulai. Pelaksanaan Inisiasi ini dilakukan di bulan pertama kegiatan dan in-isisasi terdiri dari beberapa tahapan, yaitu:

\section{a. Pembahasan Persiapan}

b. Perencanaan

Roadmap pada umumnya di awali dengan pembahasan Grand Design atau Blue Print yang sudah dimiliki. Pembahasan Rencana Kerja Jangka Panjang, selalu memiliki poin-poin tertentu yang dapat digunakan untuk pembahasan yang lebih rinci dan dapat digunakan se-bagai penyusunan roadmap dengan jangka waktu yang lebih pendek.

Sesuai dengan hal di atas, bahwa sasaran-sasaran pada tahapantahapan pelaksanaan Roadmap penting untuk memudahkan dalam hal monitoring dan evaluasi pelaksanaan. Masing-masing tahapan tersebut harus memiliki indikator pencapaian, yaitu indikator keberhasilan dari sebuah sasaran. Indikator digunakan sebagai penyusun roadmap sehingga dengan mudah dilakukan proses pelaksanaan dan monitoring evaluasi kegiatan. Indikator pencapaian yang dapat diketahui adalah tentang pelaksanaan tersebut sudah mencapai sasa-ran ataukah indikasi yang dapat menandakan bahwa sasaran-sasaran tersebut tercapai se-hingga standar keberhasilan yang diperoleh dapat dibentuk / disiapkan sejak dini.

\section{Perancangan dan Penyusunan Draft Roadmap}

Tahapan Perancangan dan Penyusunan Draft Roadmap merupakan tahap pelaksanaan dimulainya penyusunan Roadmap. Dimulai dari Pertengahan bulan Pertama hingga Perten-gahan bulan ke dua. Yaitu:

a. Perancangan

b. Penyusunan Draft Roadmap

Penyusunan Draft Roadmap dengan mengikuti tahapan persiapan di atas, melalui perolehan dan ketersediaan data dan informasi dan ditentukannya sasaran dari masing-masing tahapan, Roadmap mulai disusun sebagai pernyataan kegiatan penyusunan roadmap persandian dimulai.

Roadmap yang akan disusun, dalam hal ini dibuat dalam bentuk draft tersebut lebih mengarah pada penyusunan yang sifatnya terbagi menjadi beberapa bagian dalam hal Persandian yang sudah tentu adalah dalam hal Persandian seperti ketersediaan, penyangkalan dan otentifikasi, yaitu untuk obyek bidang:

A. Tahap Prosedur Standar Operasional Perijinan

1) Daftar Perijinan

2) Pembuatan Sertifikat elektronik

i. Tanda Tangan Digital

ii. Email Proteksi

iii. Web Proteksi 
B. Tahap Persiapan dan Sosialisasi Bimbingan Teknis Sumber Daya Manusia (SDM).

C. Tahap Infrastruktur (Prasaranan dan Sarana) dan Pendukung lainnya

1) Jaringan Komunikasi

2) IT Security Assessment

Pelaporan berikutnya adalah sebagai pelaporan di fase perancangan. Dengan dilakukan laporan pekerjaan dalam bentuk laporan antara dan dipaparkan, diperuntukan dalam rangka berita acara penyelesaian tahapan perancangan dan penyusunan draft Roadmap.

Dengan dipaparkan draft roadmap dan disepakatinya bentuk-bentuk tahapan dan sasaran Roadmap tersebut, maka kedua pihak dapat menyatakan tahapan draft penyusunan Roadmap selesai dan dapat dilanjutkan ke tahap finalisasi Roadmap. Sesuai dengan tahapan-tahapan yang telah disepakati bersama sebelumnya.

Memberikan pernyataan bahwa apa yang diharapkan sebagaimana dinyatakan dalam "Pendahuluan" akhirnya dapat diperoleh hasil dalam "Hasil dan Pembahasan", sehingga terdapat kesesuaian. Selain itu dapat juga ditambahkan prospek pengembangan dari hasil penelitian dan aplikasi lebih jauh yang menjadi prospek kajian berikutnya.

\section{Finalisasi Roadmap}

Finalisasi Roadmap dijelaskan dengan paparan Pelaporan hasil dokumen akhir dari Roadmap yang sudah disusun sebagai tahap final. Hasil lanjutan dari pembahasan Roadmap yang dilakukan di tahap sebelumnya. Dengan memverifikasi dan klarifikasi draft Roadmap terhadap user stakeholder, maka akan memberikan kepastian akan susunan Roadmap yang akan diimplementasikan.

Secara umum, langkah yang dimungkinkan adalah mengundang stakeholder terkait. Di-mana sebelumnya adalah diundang dalam rangka membantu atas dukungan pihak Eksekutif akan terbentuknya Roadmap, maka saat ini stakeholder diundang kembali untuk memasti-kan pembahasan sebelumnya dalam bentuk Uraian Tahapan sebagai Roadmap. 


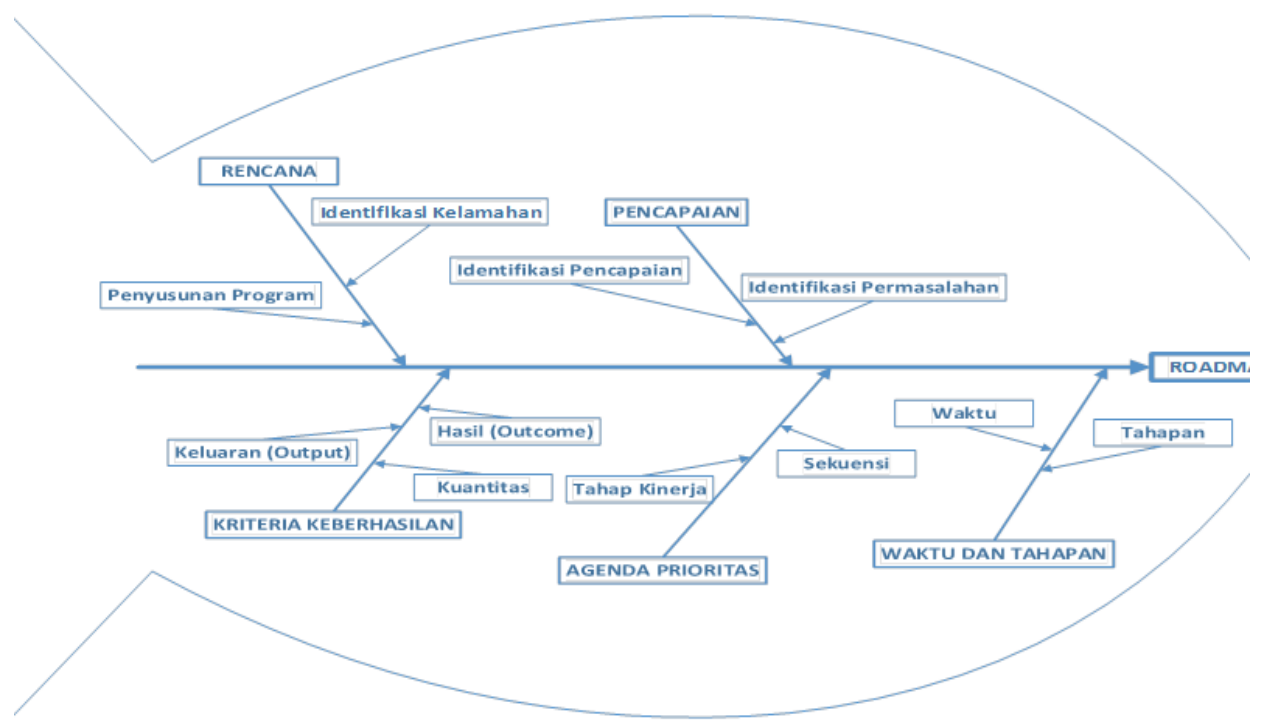

Gambar 2. Fishbone Kerangka Kebutuhan Roadmap

Menampilkan format Roadmap yang diharapkan melalui Tugas dan Fungsi dari Dinas Komunikasi dan Informatika, Bidang Statistik dan Persandian, terutama pada Seksi Persandian. Membuat Perencanaan, Pelaksanaan, Pemantauan dan Evaluasi serta Pelaporan untuk pen-capaian sasaran, dari kualitas dan kuantitas hingga sebagai referensi pembiayaan atau penganggaran kebutuhan pelaksanaan kegiatan. Tahapan roadmap, yang dihasilkan untukn rentang wak-tu 5 tahun diantaranya :

a. Menghimpun, pengolahan dan evaluasi data di lingkup Seksi Persandian;

b. Menyusun peraturan teknis tata kelola persandian untuk pengamanan informasi, meliputi : pengelolaan informasi berklasifikasi; pengelolaan sumberdaya manusia sandi; pengel-olaan perangkat lunak persandiaan; pengelolaan perangkat keras persandian dan pengel-olaan jaring komunikasi sandi;

c. Menyusun peraturan teknis operasional pengelolaan komunikasi sandi antar perangkat daerah di lingkungan pemerintah kota dan peraturan teknis operasional pengamanan komunikasi sandi;

d. Menyusun rencana kebutuhan sumberdaya manusia sandi;

e. Melakukan pengembangan kompetensi sumber daya manusia sandi melalui program pen-didikan, pelatihan, fasilitasi, asistensi, bimbingan teknis, workshop dan/ atau seminar;

f. Melakukan pemeliharaan dan perbaikan terhadap perangkat lunak persandiaan, perangkat keras persandiaan dan jarring komunikasi persandiaan;

g. Merancang pola hubungan komunikasi sandi antar perangkat daerah di lingkungan pemerintah kota; 
h. Melakukan pengadaan, penyimpanan, distribusi dan pemusnahan perangkat keras persan-dian;

i. Menyusun rencana kebutuhan perangkat keras dan perangkat lunak persandiaan dalam operasional komunikasi sandi antar perangkat daerah di lingkungan pemerintah kota;

j. Melakukan pengamanan informasi elektronik;

k. Melakukan pengelolaan Security Operation Center (SOC) dalam rangka pengamanan in-formasi dan komunikasi;

l. Melakukan pemulihan data atau system jika terjadi gangguan operasional persandiaan dan keamanan informasi;

m. Melakukan program pengawasan internal di lingkungan Seksi Persandian;

n. Melakukan bimbingan, petunjuk dan membagi tugas kepada bawahan agar pelaksanaan tugas dapat berjalan lancar.

Dokumen akhir dari kegiatan ini adalah sebagai bentuk finalisasi kegiatan. Output dari pelaksanaan tersebut adalah Roadmap yang akan diimplementasikan dalam jangka waktu tertentu, sehingga akan digunakan sebagai arahan perjalanan ke depan dalam Lembaga Persandian Pemerintahan

Referensi-referensi yang dijabarkan dan diuraikan sesuai dengan kebutuhan dalam pembu-atan Roadmap menjadikan landasan dasar pelaksanaan kegiatan Penyusunan Roadmap. Dokumentasi Finalisasi Roadmap juga sebagai penanda bahwa waktu pelaksanaan kegiatan Penyusunan Roadmap sudah berakhir. Sehingga semua aktifitas kegiatan dapat ditutup atau di-akhiri dengan masuk ke proses serah terima.

\section{SIMPULAN}

Dinas Komunikasi dan Informatika Pemerintah sebagai bagian dari salah satu stakeholder sangat mendukung akan terlaksananya kegiatan Penyusunan RoadMap Persandian. Sehingga diharapkan fungsi-fungsi bidang persandian yang memiliki peranan penting dalam pengamanan informasi publik dapat terlaksana dengan baik sesuai dengan tujuan, sasaran yang ingin dicapai dengan indikator yang disepakati bersama.

Perencanaan, Pelaksanaan, Pemantauan dan Evaluasi dan Pelaporan, dapat mendukung kemajuan dari kinerja Dinas Komunikasi dan Informatika, Bidang Statistik dan Persandian, Seksi Persandian. Sehingga Peta Jalan (RoadMap) akan memberikan referensi pencapaian (milestone) baik dari kualitas dan kuantitas maupun arahan pembiayaan/penganggaran.

RoadMap Persandian pemerintah daerah di Indonesia yang dibuat diharapkan dapat memberikan kemudahan dalam penyusunan rencana kerja dan kegiatan di Dinas Kominfo dan Informatika, Bidang Statistik dan Persandian, Seksi Persandian ke depannya sehingga fungsi pengamanan informasi publik dapat terlaksana dengan baik sesuai periode waktu yang ada. 
Sebagai saran dari kelanjutan kegiatan ini, RoadMap Persandian tersebut masih perlu dikembangkan lagi melalui pembuatan detil pelaksanaan melalui SOP (Standar Operasional Prosedur) dan IK (Instruksi Kerja) sebagai tahapan-tahapan yang komprehensif. Sehingga RoadMap dapat langsung diimplementasikan di lingkungan setempat.

\section{DAFTAR PUSTAKA}

[1] Ahmad Budiman. Urgensi Pengaturan Persandian Di Pemerintah Daerah. Majalah Info Singkat: Pemerintah Dalam Negri. 2016

[2] DISKOMINFO JATENG. Persandian Dituntut Mampu Jamin Keamanan Informasi. Diperoleh 28 November 2018, dari http://diskominfo.jatengprov.go.id/berita/persandian-dituntut-mampujamin-keamanan-informasi / (2017, 17 Oktober).

[3] Hadi WibowoApakah Persandian itu? Diperoleh 28 November 2018, dari https://hadiwibowo.wordpress.com/2009/04/11/apakah-persandian-itu/. (2009, 11 April).

[4] Orvala Rizqy. Persandian Sebagai Pengaman Informasi. Diperoleh 30 November 2018, dari https://www.academia.edu/32404569/PERSANDIAN_SEBAGAI_PENGAMA NAN_INFORMASI (2016, 31 Mei).

[5] Republik Indonesia. Undang-Undang Republik Indonesia No. 14 Tahun 2008 Tentang Keterbukaan Informasi Publik. Jakarta. 2008

[6] Republik Indonesia. Peraturan Pemerintah Republik Indonesia No. 18 Tahun 2016 Tentang Perangkat Daerah. Jakarta. 2016

[7] Republik Indonesia. Peraturan Kepala Lembaga Sandi Negara No.9 Tahun 2016 Tentang Nomen-klatur Perangkat Daerah Dan Unit Kerja Pada Perangkat Daerah Urusan Pemerintahan Bidang Persandian. Lembaga Sandi Negara. Jakarta. 2016

[8] Republik Indonesia. Peraturan Kepala Lembaga Sandi Negara No.7 Tahun 2017, Tentang Pe-doman Penyelenggaraan Persandian Untuk Pengamanan Informasi Di Lingkungan Pemerintahan Daerah Provinsi Dan Kabupaten/Kota. Lembaga Sandi Negara. Jakarta. 2017

[9] Republik Indonesia. Peraturan Presiden Republik Indonesia No.53 Tahun 2017, Tentang Badan Siber dan dan Sandi Negara. Jakarta. 2017

[10] Republik Indonesia. Peraturan Presiden Republik Indonesia No.133 Tahun 2017, Tentang Perubahan atas Peraturan Presiden Republik Indonesia No.53 Tahun 2017 tentang Badan Siber dan dan Sandi Negara. 2017

[11] Republik Indonesia. Peraturan Presiden Republik Indonesia No.133 Tahun 2017, Tentang Perubahan atas Peraturan Presiden Republik Indonesia No.53 Tahun 2017 tentang Badan Siber dan dan Sandi Negara. 2017

[12] Republik Indonesia. Pedoman Menteri Komunikasi dan Informatika No.5 Tahun 2016 Tentang Road Map Reformasi Birokrasi 2015-2019 Di Lingkungan Kementrian Komunikasi dan Informatika. Jakarta. 2016 